\title{
Percepción de los comportamientos y patrones corporales asignados a la mujer en publicidad
}

\author{
Perception of behavior and body patterns assigned to women in \\ advertising
}

\author{
Dra. Silvia Ma Vega Saldaña, Universidad de Cádiz (UCA) \\ smvsmr@yahoo.es | http://orcid.org/0000-0001-7130-5563 \\ Calle Ancha, 16, 11001 Cádiz \\ Dr. Daniel Barredo lbáñez, Universidad del Rosario (Colombia) \\ daniel.barredo@urosario.edu.co | http://orcid.org/0000-0002-2259-0756 \\ Calle $12 \mathrm{C} \mathrm{N}{ }^{\circ} 6-25$, Bogotá, Colombia \\ Dra. Ana Merchán Clavellino, Universidad de Cádiz (UCA) \\ ana.merchan@uca.es | http://orcid.org/0000-0002-0094-3100
}

\begin{abstract}
Resumen
La publicidad en pro de su fin económico y comercial sigue empleando, creando y difundiendo estereotipos femeninos disfuncionales y patriarcales, amparados en actitudes, comportamientos y patrones corporales restrictivos, que históricamente se han atribuido y asociado a las féminas para pautar, diferenciar y someter el universo de éstas al masculino. Unos estereotipos de género erigidos sobre caracteres emocionales o conductuales, como su constante feminidad, su abocada seducción, su falsa seguridad amparada en su fugaz belleza, la pasividad que la rodea y de la que se nutre, su activo narcisismo, su constante infantilización en pro de la negación de su madurez y de la vejez, su acentuada debilidad marcada por cuerpos carentes de musculatura y extremadamente delgados, o su incipiente andrógina en la que se alaban los valores masculinos. Todos estos caracteres emocionales o conductuales, que imprimen personalidad a las modelos y conforman el universo femenino, que se inmiscuyen e instauran en el contexto contemporáneo a través de la publicidad, vienen sustentados por cuerpos que presentan patrones corporales estrictos, PCE: talla $\leq 36$, altura $\geq 170 \mathrm{~cm}$. y somatotipo ectoformo, en los que impera la belleza y la juventud, y que han marcado y oprimido a la mujer fuera y dentro de los medios comunicacionales. Un hecho que la mujer real y actual es capaz de percibir e identificar claramente y con el que no se muestra conforme.
\end{abstract}

Forma de citar:

Vega S., Barredo D., y Merchán, A. (2019). Percepción de los comportamientos y patrones corporales asignados a la mujer en publicidad. Ámbitos. Revista Internacional de Comunicación, 44, 162-180. doi: 10.12795/Ambitos.2019.i44.10 


\begin{abstract}
Advertising in favor of its economic and commercial purpose continues to employ, creating and disseminating dysfunctional and patriarchal female stereotypes, protected by attitudes, behaviors and restrictive corporal patterns, which historically have been attributed and associated with females to guide, differentiate and subdue the universe from these to the masculine. Gender stereotypes erected on emotional or behavioral characters, such as her constant femininity, her doomed seduction, her false security protected by her fleeting beauty, the passivity that surrounds her and from which she feeds, her active narcissism, her constant infantilization in favor of of the denial of their maturity and old age, their marked weakness marked by bodies lacking in muscle and extremely thin, or their incipient androgynous in which masculine values are praised. All these emotional or behavioral characters, which imprint personality on the models and they make up the feminine universe, which interfere and establish themselves in the contemporary context through advertising, they are sustained by bodies that present strict corporal patterns, PCE: size $\leq 36$, height $\geq 1.70 \mathrm{~cm}$. and ectoform somatotype, in which beauty and youth prevail, and which have marked and oppressed women outside and within the media. A fact that the real and current woman is able to perceive and identify clearly and with which she does not agree.
\end{abstract}

Palabras clave: mujer, publicidad, patrón corporal, rasgos físicos, actitudes.

Keywords: woman, advertising, body pattern, physical features, attitudes.

\title{
1. INTRODUCCIÓN
}

Las revistas femeninas de alta gama, como ya advirtió Gallego (1990), tienen un alto potencial formativo para la mujer, pues a través de sus contenidos, informativos y publicitarios, se declara, postula y redefine, desde sus inicios, lo que es ser mujer. De ahí la importancia del análisis exhaustivo de los contenidos de éstas, pues entre sus páginas, anuncia Torres (2008), se propone y restringe el universo femenino. Contenidos asentado en sus ya consagrados ejes vertebrales la Belleza, el Amor y el Hogar, y que tienen su continuidad en su publicidad, en la que, declara Torres (2007), se ha instaurado un estándar de belleza restrictivo que ha calado en la audiencia. De aquí se desprende el valor de estudiar no sólo los parámetros estéticos a los que se somete a los cuerpos de la mujer en la publicidad, sino los rasgos, caracteres, actitudes y comportamientos que se imprimen e imponen a ésta y que contribuyen a conformar lo que se presupone debe ser una mujer en el contexto actual.

\section{APROXIMACIÓN A LAS ACTITUDES Y COMPORTAMIENTOS QUE SE REFLEJAN EN EL FÍSICO DE LA MUJER EN LA PUBLICIDAD Y QUE ESTÁN LIGADAS A ROLES Y ESTEREOTIPOS DE GÉNERO}

Autores como Lomas (2005) han indicado que la construcción simbólica de los géneros en la comunicación publicitaria se realiza a través de la confrontación de dos universos; quedando 
el femenino al servicio del masculino, y que se traduce, apunta Loscertales (2009), en una separación constante de los comportamientos y actitudes que la publicidad recoge y emplea en pro de sus objetivos comerciales. Empleándose los estereotipos de género no sólo para atribuir a ambos sexos las características físicas, sino también aquellos caracteres emocionales o conductuales que históricamente se ha considerado definen y pautan, a la par que diferencian, la personalidad de hombres y mujeres, según Navarro y Martín (2011). Es por ello que el estudio de los rasgos, actitudes y comportamientos que se atribuyen a las imágenes femeninas en pro de su patrón corporal en la publicidad se hace tan necesario, pues, si como afirma Pease (1991), las personas expresan estados de ánimos que pueden ser identificados por los gestos, señas o posturas que adopten, es pertinente examinar si los diferentes patrones corporales pudieran venir introducidos por diferentes rasgos, actitudes o comportamientos, que segmenten y jerarquicen el universo femenino. Un universo que como advirtió Ory (2006) está en constante movimiento, a la par que sujeto a acuerdos sociales, afectando al modo en el que las personas perciben el cuerpo físico del otro y el de ellas mismas, una interacción que agudiza el cambio constante y la manera en la que las mujeres desean ser percibidas.

\subsection{La feminidad}

Este estudio participa de la idea de que la mujer nace mujer, pero no por ello debe ser definida como un ser femenino, pues Bernárdez (2009) afirma que el concepto de <<lo femenino>> viene erigido sobre la subjetividad social y alimentada por el imaginario colectivo. De ahí que esta autora afirme que las mujeres introducidas y recreadas por los hombres respondan a una serie de caracteres que las definen y subyugan a éstos, entre las que cabe destacar la perfección estética que las envuelve, la fragilidad que las sustenta o la juventud que les han imprimido, elementos que las supeditan socialmente. En esta línea, Lomas (2005) recoge que una mujer femenina es aquella que carece de inteligencia y que todo su mundo se centra en conseguir estar bella para poder optar al hombre ideal, premisa que conllevará a que la feminidad esté reñida con la inteligencia. A lo que Santiso (2001) añade que, lo que realmente se valora y realza de una mujer es su valor corporal estético, por encima de su intelecto y otras capacidades. Además, en la sociedad contemporánea el concepto o valor de belleza queda ligado al de juventud, con lo cual una mujer será bella mientras sea joven; convirtiéndose la juventud en un valor intrínseco y exclusivo para la feminidad, lo que proporcionará una constante preocupación por el físico, lo que la re-direccionará, indica Bernárdez (2009), hacia el aprendizaje de determinadas actitudes (andar seductoramente con tacones, tocarse el pelo delicadamente, mirar de soslayo, usar medias, trenzarse el pelo, etc.). Además, la feminidad también es sinónimo de indefensión, una mujer incapaz de rescatarse a sí misma y que necesita de la figura masculina.

\subsection{Mujeres andróginas}

La androginia interviene en el proceso de la construcción de la identidad sexual femenina, e introduce y establece determinados rasgos físicos o cualidades, así como actitudes, que difieren con las que se esperan en una mujer. Por lo que indica Díez (2010), la andrógina actúe 
en publicidad en diferentes niveles abarcando desde los aspectos estético y corporales de las modelos hasta los actitudinales y comportamentales, consumándose cuando se intercambian los roles de género definidos y aceptados por la sociedad. De ahí que comience en el plano de lo físico, mujeres con el pelo corto o sin depilar..., y se extienda a la manera de vestir, gesticular, y actuar de las féminas. Sin embargo, la androginia no ha afectado a la mutabilidad del concepto de belleza con el que debe cargar la mujer y al que debe aspirar, pues tal y como anunció Peña Marín (1992), la belleza sigue considerándose el atributo más valorado en la mujer.

\subsection{Cuerpos atléticos de mujer}

Apunta Cabrera (2010) que el rasgo estético más apreciado para el hombre y que realza la estética masculina es la musculatura, mientras que en la mujer el rasgo corporal se traduce en la delgadez que presente. Una representación no casual y explícita de la inferioridad femenina de la que se hacen eco los medios de comunicación hasta la saciedad. Y es que los somatotipos corporales, apunta Sánchez (2015), también entienden de género, al atribuirse a la mujer el modelo corporal ectoformo, mientras que al hombre se le asigna el mesoformo. Unos rasgos estéticos que no sólo influyen en el canon corporal de la mujer, sino que repercuten en la actitud que ésta refleje en la ficción publicitaria.

\subsection{La infantilización de la imagen femenina}

Afirma Gallego (1990) que juventud es la fuente de la belleza y sin ésta la belleza se esfuma. En este sentido, Cáceres y Díaz (2008) reafirman la idea y la tendencia general de que la publicidad tiende a infantilizar la imagen de la mujer y, para ellos, no sólo recurre a representarla en sus edades más tempranas, sino que refuerza la carga de simbolismos, objetos, ropas, posturas, peinados, rasgos físicos o actitudes que acentúan este proceso en el que la modelo queda anclada en su infancia. Por ello, la infantilización de la mujer se instituye como otra herramienta patriarcal de las que se nutre la publicidad, con el objetivo de negar y ocultar la madurez femenina.

\subsection{La mujer seductora}

Según del Castillo, López y del Castillo-López (2009), se representa la figura de la mujer como un ser seductor, dependiente y femenino sobre el que recae el foco del deseo, mientras que la figura masculina se exhibe como un ser más moderno, autónomo, activo y ganador. Lo que se traduce en que feminidad, belleza, juventud, erotismo y seducción vayan de la mano de la mujer contemporánea, de ahí que la desnudez y los tacones de aguja inunden los spot publicitarios, indican Fernández, Baños y García (2014).

\subsection{La mujer pasiva}

La pasividad es una actitud que se atribuye histórica y mediáticamente a la mujer, recogen Espín, Marín y Rodríguez (2006), frente al hombre que se erige en una figura activa. Una pasividad femenina que se transfiere y abarca todos los planos de su vida, afectando e interfiriendo en sus 
relaciones sociales o a su limitado. Unas actitudes pasivas que se extienden hasta doblegar la quinesia femenina, al aparecer en publicidad mujeres postradas, recostadas o sentadas sobre todo tipo de objetos y superficies, indica Díaz (2007). Y que desemboca en la aparición publicitaria de mujeres frágiles, dóciles, sensuales, arraigando cada vez más el estereotipo social de una mujer pasiva, sumisa y dependiente, apunta Farré (1998), idea de la que participan autoras como Gallego (2009) o López (2005).

\subsection{La mujer segura}

La complejidad de presentar una mujer segura en los medios de comunicación radica, según Paone (2016), en que los adjetivos que concuerdan con la seguridad femenina, históricamente difundidos y aceptados, no sugieren fragilidad, sutileza o suavidad; pues una mujer segura de sí misma y de su intelecto y capacidades podría llegar a perder su parte de feminidad, dado que las actitudes que desprenden seguridad supondrían la pérdida de feminidad. De ahí que la problemática actual se geste cuando la seguridad femenina se cimienta no sobre su integridad personal o sobre su intelecto, sino que se basa en su belleza. Una belleza sobre la que se asienta el secreto del éxito de la mujer, según Lipovetsky (1999), y una seguridad que, evidentemente, la mujer perderá al envejecer, pues está fundamentada en su belleza.

\subsection{El narcisismo hecho mujer}

Si como se viene contemplando a lo largo de este artículo la cualidad más valorada de la mujer es la belleza, -dentro y fuera de los medios de comunicación y de la ficción publicitaria-, y en ella se fundamenta todo su poder femenino, las mujeres en publicidad deberán representar esta tendencia y ejercer culto a su cuerpo perfecto convertido en templo de la feminidad. Por esta razón las modelos, apunta Salazar (2007), en la ficción publicitaria aparecen en actitudes en las que se veneran a sí mismas y a la estética que poseen, convirtiéndose dicha veneración en el más intenso interés femenino y que es recogida por los anuncios publicitarios, centrados en el cuidado, contemplación y adoración de su cuerpo. Imágenes que representan la banalidad transformada en mujer y que han caracterizado, según Behar (2010), el fin del siglo XX y el comienzo del XXI.

\section{EL PATRÓN CORPORAL FEMENINO CONTEMPORÁNEO}

El patrón corporal femenino se ha ido adaptando y moldeando en pro de las distintas necesidades mediáticas y capitalista que han surgido a lo largo de la historia, concepto apoyado por Andrade (2003) o Justo y Vizeu (2012), de ahí la palpable cosificación del cuerpo de la mujer. En la actualidad, la necesidad del estudio de los patrones corporales que se dictan a las féminas en la publicidad se hace cada vez más necesaria, de ahí que autores como Martín (2002); Ruiz y Rubio (2004); Cáceres y Díaz (2008); Lomas (2005); Bernárdez (2009); Santiso (2001); Behar (2010); Soley (2010); Cabrera (2010); Bilbao (2013) o Gómez (2016) hayan estudiado por separado las diferentes cualidades estéticas (talla, altura y somatotipo) que encumbran al cuerpo femenino como a una de las herramienta publicitarias más eficaces de las que se sirve el sistema instaurado. Así pues, la agrupación y el posterior estudio de dichos caracteres corporales, que aportan valor 
a la corporalidad de las féminas, proporcionará la oportunidad de analizar y valor la existencia y la presencia mediática, de los patrones corporales estrictos, $\mathrm{PCE}$, asentados en tres parámetros fisiológicos: talla $\leq 36$, altura $\geq 1.70 \mathrm{~cm}$. y somatotipo ectoformo, así como la de los no estrictos PCNE, que son aquellos que no poseen alguna de los tres medidas que delimitan a los PCE; a la par que las connotaciones positivas y negativas que pueda conllevar en la ficción publicitaria la posesión y exhibición de uno de estos patrones estéticos.

\section{OBJETIVOS}

El estudio persigue examinar la percepción que las mujeres tienen sobre los rasgos, actitudes y comportamientos que se asignan, en función de su patrón corporal, a las imágenes femeninas en la publicidad de las revistas femeninas de alta gama. Para ello, en primer lugar, se pretende observar si las mujeres perciben el patrón corporal imperante en la publicidad con el objeto de averiguar si se identifican con éste y con las atribuciones actitudinales y comportamentales que recaen sobre el mismo.

\section{METODOLOGÍA}

En el método aplicado en esta investigación confluyen dos vertientes metodológicas, la cuantitativa y la cualitativa. En primer lugar y en consonancia con investigaciones anteriores (Balaguer, 1985; del Moral, 2000; Loscertales, 2003; García Reyes, 2003; Ruiz y Rubio, 2004; Berganza y del Hoyo, 2006; Díaz y Muñiz, 2007; Cáceres y Díaz, 2008; Díaz, Muñiz y Cáceres, 2009; Piñeiro, 2010; y Gómez, 2016) se ha confeccionado un Libro de Códigos que ha facilitado el posterior análisis de contenido a la codificadora que ha llevado a cabo la primera etapa metodológica. Dicho Libro de Códigos integra en su interior, en primer lugar, una Ficha Inicial Clasificatoria en la que se han agrupado los datos de control de las imágenes que conforman la muestra. $Y$ en segundo lugar una Ficha de Análisis Dimensional, que aúna la Dimensión Corporal, en la que se recogen las variables corporales: talla / altura / somatotipo. Y la Dimensión Actitudinal: rasgos afeminados / rasgos andróginos / rasgos complexión atlética / rasgos infantiles / actitud seductora / actitud pasiva / actitud segura / actitud narcisista. Por su parte para llevar a cabo el establecimiento de la metodología cualitativa, se configuraron los Grupos Focales; herramienta que facilitó la aproximación y el contacto, de una forma activa, que no invasiva, con la mujer real y contemporánea, objeto de este estudio. Con este fin, y siguiendo a Guerrero (2008), se abogó por el uso del grupo de discusión extendido, una herramienta que permite la inclusión de un Cuestionario Inicial. Tal cuestionario aunó dos áreas, en la primera se establecieron las preguntas control: edad/ nacionalidad/ nivel de estudios/ ocupación actual/ maternidad/ estado civil. Y en la segunda, en consonancia con la herramienta metodológica implementada en la primera fase, el Libro de Códigos, se establecieron, en primer lugar, las siguientes cuestiones de acuerdo a la Dimensión Corporal: <<Indique, en general, ¿cómo son las mujeres que aparecen en la publicidad de la muestra?: talla / altura / somatotipo >>. <<Seleccione una casilla del 1 (no) al 7 (totalmente) según considere que posea los siguientes atributos $<36$, altura $>170 \mathrm{~cm}$, somatotipo ectoformo $>$. 
Y en segundo lugar se introdujo la Dimensión Actitudinal: <<Seleccione una casilla del 1 (no) al 7 (totalmente) según considere que las modelos de la muestra posean atributos, rasgos físicos, actitudes o comportamientos: femeninos / infantiles / andróginos / atléticos / pasividad / seguridad / seducción / narcisismo >>. « Seleccione una casilla del 1 (no) al 7 (sí, totalmente) según considere que usted posea atributos, rasgos físicos, actitudes o comportamientos: femeninos / infantiles / andróginos / atléticos / pasividad / seguridad / seducción / narcisismo >>. Además, en pro del desarrollo positivo de las sesiones focales se configuró un guion, también en equilibrio con la metodología aplicada, en el cual se insertaron las siguientes cuestiones: ¿Percibís los PCE en las modelos de la publicidad de la muestra? ¿Os identificáis corporalmente con el PCE que presentas las modelos? / ¿Qué rasgo o características percibís como el más representativo de la mujer en la publicidad? Femenina, infantil, andrógina o atlética / ¿Qué actitud o comportamiento percibís como el más representativo de la mujer en la publicidad? Pasividad, seguridad, seducción o narcisismo. I ¿Qué opináis de los rasgos, actitudes y comportamientos que habéis percibido con mayor asiduidad? / ¿Os veis reflejadas en los rasgos, actitudes y comportamientos que hemos abordado?/ ¿Os identificáis con el tipo de mujer que aparece en la publicidad de la muestra que habéis tenido oportunidad de visionar?

\section{MUESTRA}

La muestra, compuesta por 1520 imágenes femeninas, sobre la que se ha realizado esta investigación y que hace referencia a las siguientes revistas: Cosmopolitan, Elle, Glamour, Telva y Vogue, ha sido obtenida, mediante muestreo no probabilístico de selección experta, de las 5 revistas femeninas de alta gama españolas que a lo largo del año 2014 obtuvieron índices positivos en cuanto a posicionamiento y difusión, es decir, que se ubicaron entre los primeros puestos de las 25 revistas con más lectores mensuales, y con una tirada y difusión media más elevada según el Estudio General de Medios (EGM) y la Oficina de Justificación de la Difusión (OJD) respectivamente.

La muestra sobre la que se proyectaron los grupos focales se ha confeccionado a través del muestreo no probabilístico por cuotas conforme a los procedimientos de idoneidad propuestos por Alaminos y Castejón (2006), al igual que los criterios de inclusión y exclusión: sexo y edad. El aforo de los grupos, atendiendo a Aigneren (2002), se estableció con un mínimo de seis participantes y un máximo de doce. El proceso de reclutamiento de las componentes se llevó a cabo siguiendo las directrices de Juan y Roussos (2010). Por último, en consonancia con Gil-Flores (2009), la edad se fijó como un elemento diferenciador, distribuyéndose a las participantes en dos segmentos, el primero con 45 años o menos; y, por otra parte, el segundo con 46 años o más.

La introducción de estos criterios de selección y exclusión dio forma a los grupos focales:

Grupo A: mujeres no jóvenes > 46 años (8 componentes).

Grupo B: mujeres no jóvenes $>46$ años (8 componentes).

Grupo C: mujeres jóvenes $\leq 45$ años (6 componentes). 
Grupo D: mujeres jóvenes $\leq 45$ años (7 componentes).

Finalmente todas las participantes dispusieron de una semana, antes de cada sesión, para poder visionar las 152 imágenes, extraídas aleatoriamente, que conforman el 10\% de la muestra base.

\section{ANÁLISIS DE DATOS}

El procesamiento del análisis estadístico de los datos se ha llevado a cabo mediante el paquete SPSS versión 20.0. Los datos descriptivos para las variables cualitativas han sido presentados mediante prevalencias o porcentajes. Se ha empleado la prueba del Chi-cuadrado con el objeto de examinar la relación o independencia entre las variables categóricas que han formado parte de este estudio. Para las variables cuantitativas, los datos descriptivos se han presentado en medias y desviaciones típicas. Y las comparaciones entre los patrones corporales - PCE y PCNE - para cada una de las dimensiones, que han dado forma a este artículo, se han llevado a cabo a través de la ejecución de la prueba no paramétrica U de Mann-Whitney.

\section{RESULTADOS}

En primer lugar, de las 1520 imágenes analizadas, 1385 han presentado un canon estético restrictivo, lo que indica que más del $90 \%$ de la muestra examinada introduce un PCE, frente a las 135 en las que se ha apreciado un PCNE. Datos que enlazan con los resultados extraídos del cuestionario inicial realizado por las participantes, que han percibido un $100 \%$ de imágenes femeninas que poseen una talla igual o inferior a la 36 , un $100 \%$ de modelos que superan o igualan el 170 centímetros, y un $96.6 \%$ de féminas que poseen un somatotipo ectoformo. En cuanto a la identificación corporal de las participantes, respecto a las modelos de la muestra, mostraron una media muy baja, de 1.86 puntos (D.T. $=1.46)$, en lo que respecta a la percepción que tenían sobre su propio patrón corporal, lo que anunció que las colaboradoras no se identificaban corporalmente con el PCE; a lo que ha de sumarse que a lo largo de las sesiones focales se advirtió un deseo latente de semejanza corporal hacia las modelos en general, envuelto en inconformidad e insatisfacción corporal física, resultados que siguen las directrices de Etcoff, Orbach, Scott, y D’Agostino, (2004) y Dohnt y Tiggemann (2006).

A continuación se realizó un acercamiento general a los rasgos, características físicas, actitudes y comportamientos presentes en la muestra.

Tabla 8.1. Representación de los estereotipos físicos y comportamientos, de acuerdo a las imágenes de las revistas femeninas españolas de alta gama consultadas (2014)

\begin{tabular}{lcc}
\hline & M & D.T. \\
\hline Rasgos y actitudes afeminadas & 5.24 & .87 \\
Complexión atlética & 3.95 & .43 \\
Rasgos y actitudes infantiles & 1.83 & 1.30 \\
Rasgos y actitudes andróginos & 1.37 & 1.04 \\
\hline
\end{tabular}

Fuente: Tabla de creación propia 
La lectura de los datos (véase Tabla 8.1) manifiesta que las modelos ostentan un alto grado de connotaciones femeninas, independientemente del rol o estereotipo que se le asignen, hecho anunciado por Díaz (2007). En cuanto a las puntuaciones que ha obtenido la corporalidad femenina atlética, de 3.95 puntos (D.T. = .43), siguen la línea de investigaciones como la de Lara (2015), que asocian los cuerpos atléticos y musculosos a los hombres y los frágiles y delgados a las mujeres. Los rasgos y actitudes infantiles han presentado una presencia no elevada, pero sí constante de la infantilización de las modelos, en consonancia con los estudios acuñados por Díaz (2007), Cáceres y Díaz (2008) y Díaz, Quintas y Muñiz (2010). Finalmente, la androginia publicitaria es la cualidad que menor índice de puntuación ha obtenido.

A continuación se establecen las diferencias entre los patrones corporales en función de los rasgos, actitudes y comportamientos afemeninos, infantiles, andróginos y atléticos. Los resultados (véase Figura 8.1) apuntan que existen diferencias estadísticamente significativas en los rasgos afeminados entre el PCE y el $P C N E, U=57122 ; p=.000$, obteniendo mayor puntuación el PCE que superaba al PCNE en 0.59 puntos. Al estudiar la complexión atlética, también se han descubierto diferencias estadísticamente significativas, de tal manera que que el PCE, $U=$ $62834.5 ; p=.000$ son consideradas más atléticas que las mujeres que representan el PCNE. También se han hallado diferencias estadísticamente significativas en los rasgos infantiles, $\mathrm{U}=$ $69053.5 ; p=.000$, que han obtenido en la Escala Likert una puntuación de 0.63 puntos por encima de la Media del PCNE. Esta tendencia, en cambio, se ha invertido en los rasgos andróginos, $U=$ $88884.5 ; p=.107$, no hallándose diferencia estadísticamente significativa entre los patrones.

Figura 8.1. Representación de patrones corporales en función de rasgos, actitudes y comportamientos femeninos, infantiles, andróginos y atléticos, de acuerdo a las imágenes de las revistas femeninas españolas de alta gama consultadas (2014)

Fuente: elaboración propia

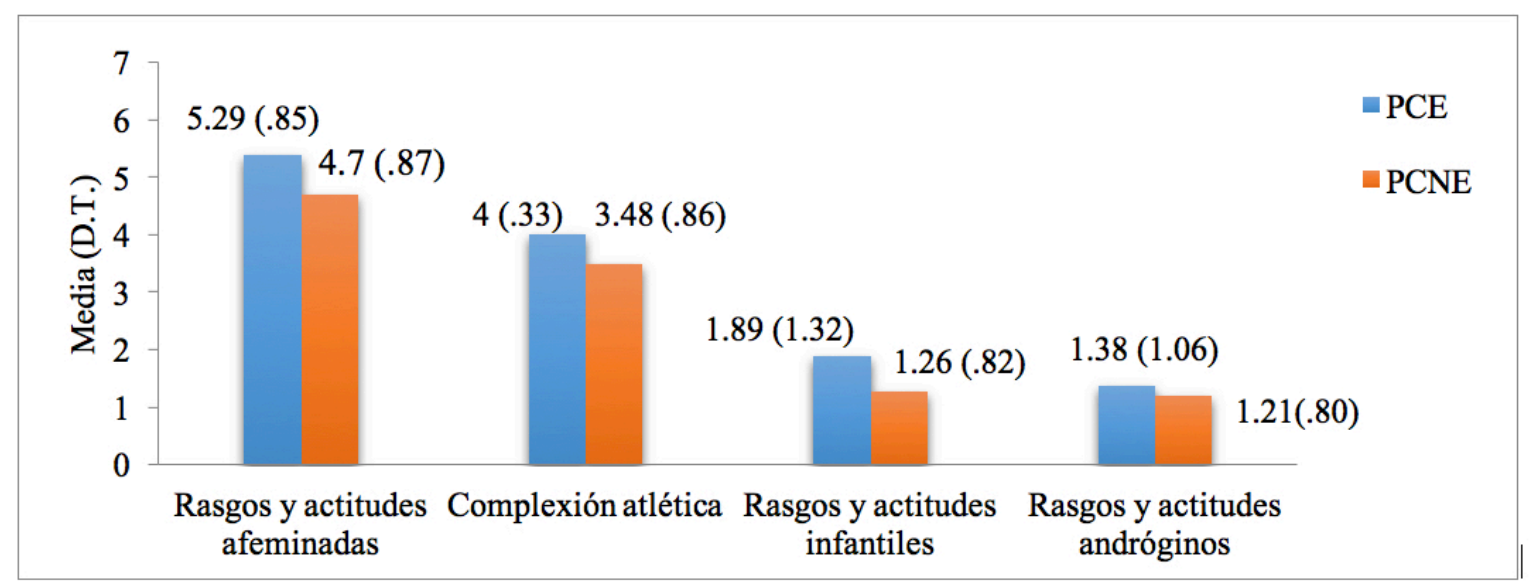

Estos datos manifiestan que el PCE introduce mujeres muy femeninas e infantilizadas, alejadas de rasgos andróginos o fuertes complexiones atléticas; mientras que los PCNE, por su parte, son asociados con los rasgos físicos y actitudes andróginas que presentan las modelos de la muestra. 
Los parámetros de percepción de las componentes de los grupos focales en pro de los rasgos físicos, caracteres, actitudes o comportamientos atribuidos a las modelos desentrañó (véase Figura 8.2) que las participantes identificaban con facilidad los rasgos y actitudes femeninas en la publicidad de la muestra, consagrándose éstos como altamente perceptibles, y alcanzando una media muy alta de 5.93 puntos (D.T. $=1.16)$. Este hecho, incorpora la idea de que estos rasgos son percibidos e identificados fácilmente por las mujeres por su arraigo y abundancia en la sociedad y, por ende, en la publicidad que se hace eco de ésta; pues como afirman del Moral (2002) o Díaz (2007), independientemente de la faceta o rol en la que se enmarque a la mujer en publicidad, ésta deberá ser femenina.

Figura 8.2. Percepción de rasgos, actitudes y comportamientos femeninos, infantiles, andróginos y atléticos en la publicidad, según las mujeres participantes en los grupos focales (2014)

Fuente: elaboración propia

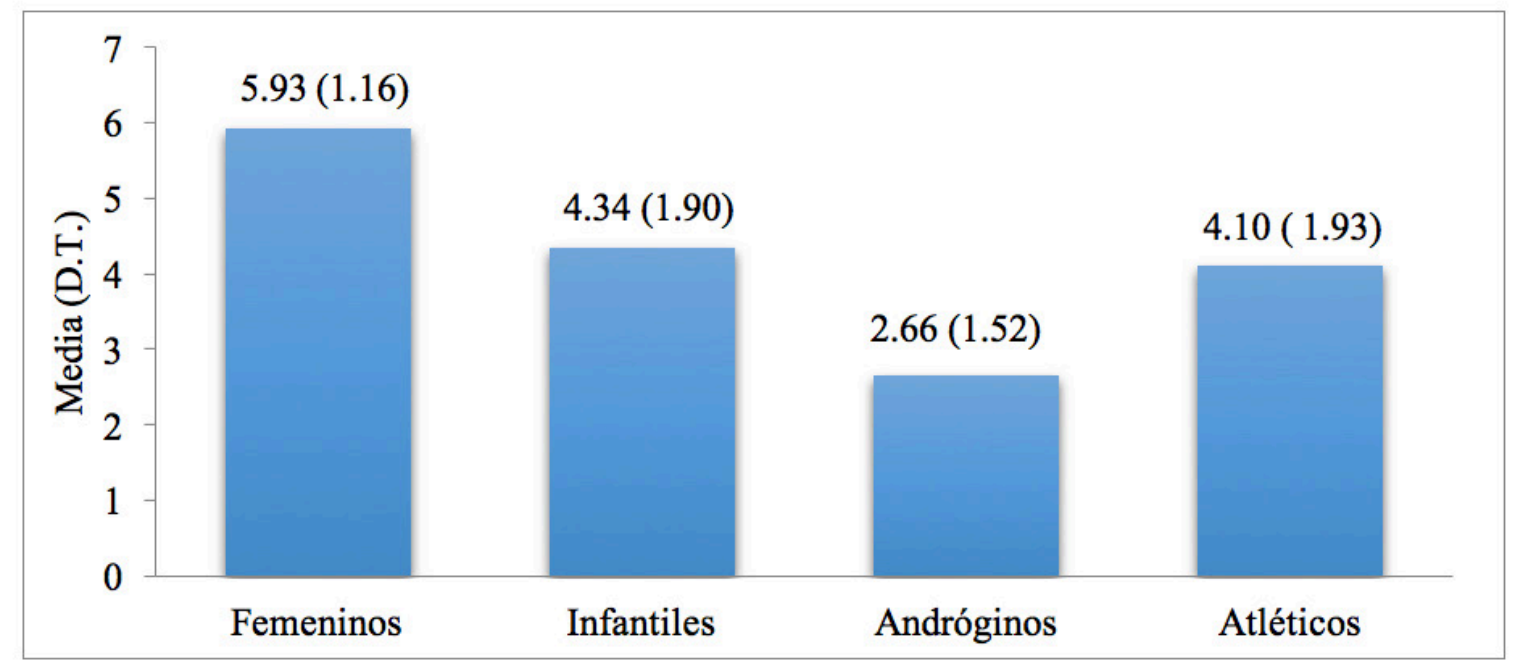

Los rasgos y actitudes infantiles y complexiones atléticas (véase Figura 8.2) obtuvieron también puntuaciones elevadas y muy igualadas, en el cuestionario inicial, con una media de 4.34 puntos (D.T. $=1.90)$ y 4.10 puntos (D.T. $=1.93)$ respectivamente, lo que señala que ambos son fácilmente reconocibles para las mujeres, como ya señalaron Díaz (2007), Cáceres y Díaz (2008) y Díaz et al. (2010). Sin embargo, los rasgos y actitudes andróginas, a pesar de estar presentes, no fueron percibidos con tanta fuerza con una media de 2.66 puntos (D.T. $=1.52$ ). Pero cuando se preguntó a las colaboradoras, de nuevo, por la percepción de dichos rasgos, actitudes y comportamientos en sí mismas, en el cuestionario inicial (véase Figura 8.3), los índices de la media se desplomaron. En primer lugar, la complexión atlética, obtuvo una media de 2.48 puntos (D.T. = 1.50). En segundo lugar quedaron los rasgos infantiles con una puntuación de 2.34 (D.T. = 1.78) que tampoco sobrepasaron la media de 3.5 puntos, y a pesar de ser un recurso constante y latente en publicidad como indican Díaz (2007); Cáceres y Díaz (2008), o Díaz et al. (2010), las participantes no se han identificado con él. Y, por último, los rasgos andróginos, han sido los menos valorados en cuanto a identificación con los mismos, con un 1.83 de media (D.T. = 1.23). 
Figura 8.3. Índice de identificación respecto de los rasgos, actitudes y comportamientos femeninos, infantiles, andróginos y atléticos en la publicidad, según las mujeres participantes en los grupos focales (2014)

Fuente: elaboración propia

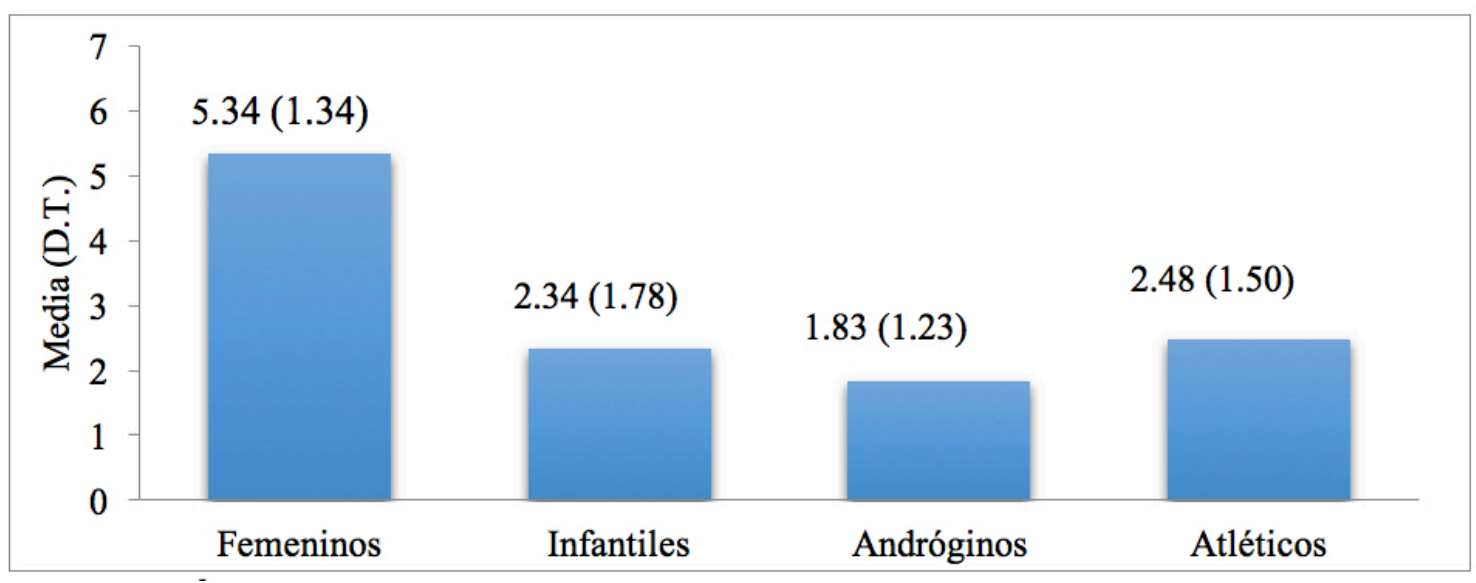

Curiosamente, sólo los rasgos y comportamientos femeninos sobrepasaron la media con un 5.34 (D.T. = 1.34), lo que evidencia que las mujeres (véase Figura 8.3) tienden a identificarse a sí mismas como a seres femeninos. Además, en las reuniones focales se desprendió la idea de que las mujeres en publicidad eran sumamente femeninas, pero dejaron patente que ellas también podían serlo y, de hecho, se ratificaban en ello. Y es que como pudo observarse, todas las participantes advirtieron que la característica que impregnaba y primaba en las imágenes de mujeres en publicidad era la feminidad. Finalmente no hubo un acuerdo tácito, en ninguno de los grupos, a la hora de dictaminar si alguno de los tres indicadores percibidos restantes (rasgos, actitudes y comportamientos infantiles, andróginos y atléticos) se impusiera a los otros dos.

A continuación se han analizado los cuatro indicadores que hacen referencia a campos de actitud y comportamiento: pasividad, narcisismo, seguridad y seducción; en primer lugar, se valoró la presencia de dichas actitudes a nivel general en la muestra. Los resultados extraídos de la primera fase metodológica mostraron que 1476 imágenes femeninas fueron percibidas como seguras, 1424 como pasivas, 1327 como narcisistas y 1058 como seductoras. Los datos del cuestionario inicial realizado por las participantes revelaron que éstas percibieron en un $97.1 \%$ a las modelos en poses y actitudes que desprendían seguridad, una seguridad infundada según Sánchez Aranda (2003) o Paone (2016) en su belleza y no en su intelecto. En segundo lugar, con un $93.7 \%$ las imágenes de la muestra fueron percibidas en facetas pasivas, una actitud que por tradición, señala Espín et al. (2006) ha sido adjudicada a la mujer. La siguiente variable contemplada, el narcisismo, enfatiza el tributo al cuerpo rendido por la publicidad con un $87.3 \%$, un hecho ya advertido por Díaz (2007). Por último, Díaz (2007) y del Castillo et al. (2009) anunciaron el alto contenido de imágenes femeninas que utilizaban su belleza para así mostrarse seguras de sí mismas y seducir a la figura masculina; un comportamiento que en el presente estudio obtuvo un $69.6 \%$. 
A continuación, en relación con el trabajo realizado se observaron las actitudes y comportamientos de seguridad, pasividad, narcisismo, y seducción en función de los PC.

Figura 8.4. Representación de la percepción de actitudes y comportamientos de seguridad según patrones corporales, de acuerdo a las imágenes de las revistas femeninas españolas de alta gama consultadas (2014)

Fuente: elaboración propia

\begin{tabular}{|c|c|c|c|}
\hline $100 \%$ & \multirow{5}{*}{$98.6 \%$} & $18.5 \%$ & \multirow{6}{*}{$\begin{array}{l}\text { No seguras } \\
\text { Seguras }\end{array}$} \\
\hline $80 \%$ & & \multirow{4}{*}{$81.5 \%$} & \\
\hline $60 \%$ & & & \\
\hline $40 \%$ & & & \\
\hline $20 \%$ & & & \\
\hline & PCE & PCNE & \\
\hline
\end{tabular}

Se desvela que existe relación entre los patrones corporales y la variable seguridad, $X 2=147.55$; $p=.000$, desvela que existen diferencias estadísticamente significativas entre ambos patrones corporales y, en este sentido, la seguridad se percibe con más asiduidad en los PCE (véase Figura 8.4). Lo que relaciona la seguridad femenina con un cuerpo delgado, alto y estilizado, en consonancia con Cabrera (2010), quien afirmó que la delgadez es sinónimo de seguridad femenina.

Figura 8.5. Representación de la percepción de actitudes y comportamientos de pasividad según patrones corporales, de acuerdo a las imágenes de las revistas femeninas españolas de alta gama consultadas (2014)

Fuente: elaboración propia

\begin{tabular}{|c|c|c|c|}
\hline $100 \%$ & $5.6 \%$ & $13.3 \%$ & \multirow{6}{*}{$\begin{array}{l}\text { No pasivas } \\
\text { Pasivas }\end{array}$} \\
\hline $80 \%$ & \multirow{4}{*}{$94.4 \%$} & \multirow{4}{*}{$86.7 \%$} & \\
\hline $60 \%$ & & & \\
\hline $40 \%$ & & & \\
\hline $20 \%$ & & & \\
\hline $0 \%$ & PCE & PCME & \\
\hline
\end{tabular}


La prueba del Chi-cuadrado, $\mathrm{X} 2=12.33 ; \mathrm{p}=.000$, muestra una relación significativa. Por tanto, desveló que las actitudes de pasividad se muestran más en los PCE (véase Figura 8.5), mientras que las mujeres con PCNE se alejan de ésta.

Figura 8.6. Representación de la percepción de actitudes y comportamientos narcisistas según patrones corporales, de acuerdo a las imágenes de las revistas femeninas españolas de alta gama consultadas (2014)

Fuente: elaboración propia

\begin{tabular}{|c|c|c|c|}
\hline $100 \%$ & $8 \%$ & \multirow{3}{*}{$60.7 \%$} & \multirow{6}{*}{$\begin{array}{l}\text { No narcisistas } \\
\text { Narcisistas }\end{array}$} \\
\hline $80 \%$ & \multirow{4}{*}{$92 \%$} & & \\
\hline $60 \%$ & & & \\
\hline $40 \%$ & & & \\
\hline $20 \%$ & & $39.3 \%$ & \\
\hline & PCE & PCNE & \\
\hline
\end{tabular}

La prueba del Chi-cuadrado, $\mathrm{x} 2=308.50 ; p=.000$, muestra la existencia de dependencia entre las variables, relacionándose las actitudes narcisistas a aquellas figuras femeninas que presentan PCE (véase Figura 8.6). Esto puede suceder porque iría contra la propia publicidad contemporánea que idolatra, proclama y vende la perfección corporal, el que una mujer que no posee un PCE se mostrase orgullosa y venerase su cuerpo.

Figura 8.7. Representación de la percepción de actitudes y comportamientos de seducción según patrones corporales, de acuerdo a las imágenes de las revistas femeninas españolas de alta gama consultadas (2014)

Fuente: elaboración propia

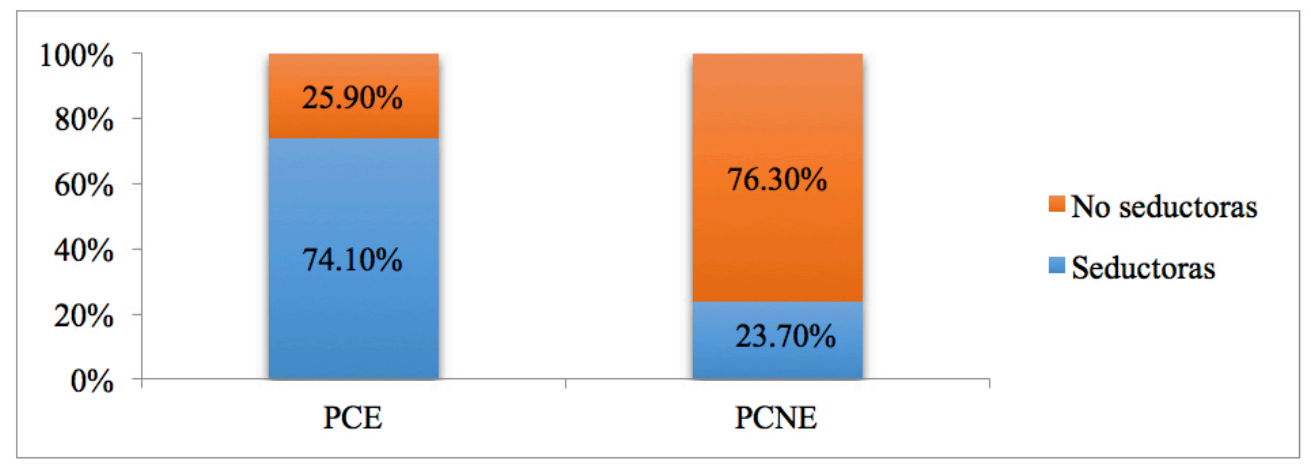


Los datos muestran que existe relación entre seducción y patrones corporales, $X 2=147.55$; $p=.000$, relacionándose las actitudes de seducción a aquellas figuras femeninas que presentan un PCE (véase Figura 8.7). Lo que indica que las imágenes femeninas que se representan con un mayor poder de seducción, son aquellas que cumplen el PCE, es decir, aquellas que se sienten seguras por su físico.

En consonancia con los datos obtenidos en la primera fase metodológica, las participantes, a través del cuestionario inicial, percibieron en un $100 \%$ la seducción como la actitud o comportamiento que primaba en las modelos y que, por ende, las caracterizaba; a la que se sumó la seguridad, con un $86.2 \%$; ambas, las más sobresalientes, son justamente con las que las colaboradoras han indicado sentirse más identificadas (véase Figura 8.8). Concretamente, la seguridad ha obtenido un 4.86 de media (D.T. = 1.66), y a la que siguen las actitudes de seducción, con un 3.86 de media (D.T. $=1.60)$, unos resultados que reflejan que las mujeres que han colaborado en las sesiones tienden a sentirse seguras y seductoras. Actitudes que, siguiendo Sánchez Aranda (2003) o Paone (2016), se sustentan en la belleza y perfección corporal de las modelos publicitarias. Precisamente estas dos actitudes fueron las más criticadas y sobre las que se centraron los debates focales que asociaron seguridad y seducción a la belleza y perfección de las modelos; sin ellas, las modelos perderían todo su poder, introduciendo así el concepto de falsa seguridad sostenida por su belleza. En tercer lugar, las modelos fueron identificadas como narcisistas con un $79.4 \%$, es decir, las mujeres percibieron que las imágenes femeninas se veneraban e idolatraban en demasía, pues según las participantes todo su mundo se centraba en su físico y el cuidado de él; sin embargo, no destacaron dicha condición en sí mismas al tener que definirse (véase Figura 8.8).

Figura 8.8. Índice de identificación de actitudes y comportamientos reflejados en las imágenes femeninas de las revistas femeninas españolas de alta gama consultadas (2014)

Fuente: elaboración propia

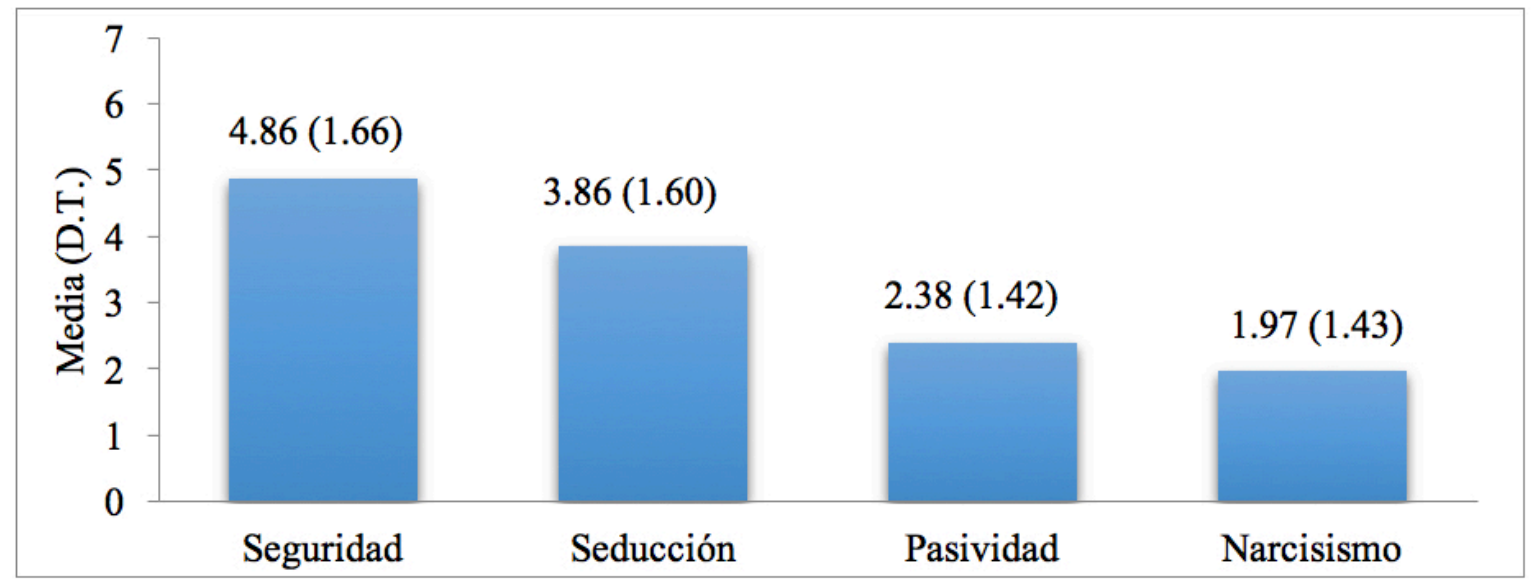

Y, finalmente, la actitud que indica pasividad fue la que menor puntuación obtuvo, pues sólo aproximadamente la mitad de las participantes, el 55.2\%, lograron identificarla a nivel general 
a través de las imágenes femeninas que componen la muestra, y con la que las mujeres no se identificaron y que sólo alcanzó un 2.38 de media (D.T. = 1.42). Además, dicha actitud no fue bien recibida por las mujeres que asistieron a las reuniones, la cual asociaban a la belleza que están poseían y que les abría tantas puertas que no necesitaban ser proactivas. A modo de cierre cabe concretar que las participantes de las sesiones focales establecieron que entre las cuatro actitudes percibidas (seguridad, seducción, narcisismo y pasividad), existía una simbiosis. Y achacaron el que todos estos rasgos se encontrasen en las imágenes femeninas de la muestra porque todas eran bellas y la belleza traía consigo dichas actitudes que caracterizaban a las modelos.

\section{DISCUSIÓN Y CONCLUSIONES}

A pesar de las limitaciones enfrentadas por esta investigación -como la existencia de una única codificadora, encargada de realizar la primera fase metodológica, o la imposibilidad de mostrar a las integrantes de los grupos focales las 1520 imágenes que componen la muestra total-, el estudio ha esclarecido la preeminencia de un patrón corporal restrictivo que tiende a imponerse a las mujeres desde la publicidad de las revistas abordadas. En ese sentido, este modelo de belleza contemporáneo se erige sobre tres parámetros corporales: talla $\leq 36$, altura $\geq 170 \mathrm{~cm}$. y somatotipo ectoformo, que configuran un patrón corporal estricto (PCE). Las mujeres consultadas no sólo perciben e identifican sin dificultad dicho patrón, sino que incluso les es familiar al establecer una orientación aspiracional: desean asemejarse a él, lo cual genera un sentimiento de insatisfacción. Además, se ha observado que al PCE se le atribuyen también determinados rasgos y comportamientos -como la feminidad o la seguridad-, de tal manera que sus atributos físicos proyectan asimismo actitudes y cualidades que deben formar parte de las mujeres. De modo que estas publicaciones femeninas proponen una dicotomía basada en los valores de un imaginario patriarcal. Las mujeres -según interpretamos-, deben luchar por alcanzar los estándares propuestos por el PCE, aunque en esta búsqueda de la perfección corporal se sacrifiquen, en gran medida, sus posibilidades de realización personal. Por su parte, quienes obvien estos preceptos y se labren una trayectoria identificada por el esfuerzo intelectual, posiblemente terminarán definidas por un PCNE.

Desde nuestro punto de vista, a través de las representaciones sociales que se originan en los mensajes periodísticos, es posible incentivar una mayor innovación en los roles tradicionalmente asignados a las mujeres. La publicidad, en ese sentido, configura patrones aspiracionales con la finalidad de ofrecer estilos de vida inalcanzables, solo adquiribles momentáneamente a través de la compra del producto o servicio vinculado. Mediante la construcción de dichas representaciones, por tanto, se configuran complejos entramados simbólicos que tienen un efecto, en este caso, en sus usuarias.

En conclusión, pensamos que las revistas femeninas de alta gama tienen la oportunidad de construir un perfil que erosione las dicotomías simbólicas excluyentes (atributos físicos, rasgos intelectuales), en aras de ampliar el entramado de actitudes y comportamientos que caracterizan a la sociedad consumista, capitalista y patriarcal, y de construir un modelo publicitario que favorezca el empoderamiento femenino, y no que lo cosifique a partir de sus atributos físicos. Así pues, 
este estudio propone nuevas ideas para la interesante línea de investigación que relaciona a la representación periodística, con los roles sociales y profesionales de las mujeres, así como con las percepciones que las mujeres reales tienen de este fenómeno.

\section{REFERENCIAS}

Aigneren, M. (2002). La técnica de recolección de información mediante grupos focales. La Sociología en sus escenarios, 6, 1-32. Recuperado de http://aprendeenlinea.udea.edu.co/revistas/index.php/ ceo/article/view/1611/1264

Alaminos, A. y Castejón, J.L. (2006). Elaboración, análisis e interpretación de encuestas, cuestionario y escalas de opinión. Alicante, España: Marfil.

Andrade, S. (2003). Saúde e beleza do corpo feminino - algumas representações no Brasil do Século XX. Movimento, 9(1), 119-143. Recuperado de https://seer.ufrgs.br/Movimento/article/ viewFile/2665/1298

Balaguer, Ma L. (1985). La mujer y los medios de comunicación.: el caso de la publicidad en televisión. Málaga, España: Arguval.

Behar A., R. (2010). La construcción cultural del cuerpo: El paradigma de los trastornos de la conducta alimentaria. Revista Chilena de Neuro-Psiquiatría, 48(4), 319-334. doi: 10.4067/S071792272010000500007

Bernárdez A. (2009). Representación de lo femenino en la publicidad. Muñecas y mujeres: entre la materia artificial y la carne. Cuadernos de Información y Comunicación, 14, 269-284. Recuperado de https://eprints.ucm.es/10477/1/mu\%C3\%B1ecas_y_mueres.pdf

Bilbao, L. (2013). El cuerpo, imagen de una cultura: la representación del cuerpo de "la mujer" en la publicidad. Un acercamiento hacia la construcción de la imagen femenina actual comoescaparate de su identidad. (Tesis doctoral). Universidad del País Vasco, Bilbao, España.

Cabrera, Y. (2010). El cuerpo femenino en la publicidad. Modelos publicitarios: entre la belleza real, la esbeltez o la anorexia. Icono 14(8), 223-243. doi: 10.7195/ri14.v8i3.236

Cáceres Zapatero Mª.D. y Díaz Soloaga, P. (2008). El uso del cuerpo en la publicidad de marcas de moda de lujo. Investigar la comunicación. En actas del Congreso Internacional de la AE-IC. Recuperado de http://www.ae-ic.org/santiago2008/contents/pdf/comunicaciones/108.pdf

Del Castillo, J. A. G., López, C., Soler, M. D. C. Q. y del Castillo-López, Á. G. (2009). Descripción y análisis de la publicidad de alcohol en la revista Muy Interesante. Revista Latina de Comunicación Social, 64, 461-468. doi : 10.4185/RLCS-64-2009-837-461-468

Del Moral Pérez, M. E. (2000). Los nuevos modelos de mujer y hombre a través de la publicidad. Comunicar, 14, 208-217. Recuperado de https://www.revistacomunicar.com/index.php?contenido=detalles\&n umero=14\&articulo=14-2000-27 
Dohnt, H. y Tiggemann, M. (2006). The Contribution of Peer and Media Influences to the Development of Body Satisfaction and Self-Esteem in Young Girls: A Prospective Study. Developmental Psycology, 42(5), 929 - 936. doi: 10.1037/0012-1649.42.5.929

Díaz Soloaga, P. (2007). Valores y estereotipos femeninos creados en la publicidad gráfica de las marcas de moda de lujo en España. Anàlisi, 35, 27-45. Recuperado de https://ddd.uab.cat/pub/analisi/02 112175n35/02112175n35p27.pdf

Díaz Soloaga, P. y Muñiz, C. (2007).Valores y estereotipos femeninos en la publicidad gráfica de las marcas de moda de lujo en España. Zer, 23, 75-94. Recuperado de http://www.ehu.eus/ojs/index. php/Zer/article/view/3644/3276

Díaz Soloaga, P., Muñiz, C. y Cáceres Zapatero, D. (2009). Consumo de revistas de moda y efectos en la autopercepción del cuerpo de mujeres: un estudio comparado entre España y México desde la Tercera Persona. Comunicación y sociedad, XXII, 2, 221-242. Recuperado de http://dadun.unav. edu/bitstream/10171/8681/1/20091202123453.pdf

Díaz Soloaga, P., Quintas Froufe, N. y Muñiz, C. (2010). Cuerpos mediáticos versus cuerpos reales. Icono 14, 8(3), 244 - 256. doi: 10.7195/ri14.v8i3.237

Díez Puertas, E. (2010). Cuerpos andróginos en la publicidad televisiva. Comunicación y desarrollo en la era digital. Comunicado llevado a cabo en el II Congreso Internacional de la Asociación Española de Investigación en la Comunicación. Málaga. Recuperado de: http://www.aeic2010malaga.org/ upload/ok/4.pdf

Espín, V., Marín, Ma. A. y Rodríguez, M. (2006). Las imágenes de las mujeres en la publicidad: estereotipos y sesgos. Redes.com, 3, 77-90. Recuperado de https://dialnet.unirioja.es/servlet/ articulo? codigo $=3664567$

Etcoff, N., Orbach, S., Scott, y D'Agostino, H. (2004). The real truth about beauty: a global report. Recuperado de: http://www.clubofamsterdam.com/contentarticles/52\%20Beauty/dove_white_paper_final.pdf

Farré, A. F. (1998). La mires como la mires, no la verás: el doble estándar del envejecimiento en la publicidad televisiva. Comunicación \& cultura, 3, 29-40. Recuperado de https://dialnet.unirioja.es/ servlet/articulo? codigo $=2901264$

Fernández, P., Baños, M. y García, F. (2014). Análisis iconográfico de la publicidad audiovisual de perfumes. El caso de J'Adore. Icono 14, 12, 398-430. doi: 10.7195/ri14.v12i1.549

Gallego, J. (1990). Mujeres de papel. De Hola a Vogue: La prensa femenina en la actualidad. Barcelona, España: Icaria.

Gallego, J. (2009). La construcción del género a través de la publicidad. En Actas del Congreso La construcción del género en la publicidad en el siglo XXI. Recuperado de http://www3.udg.edu/ publicacions/vell/electroniques/congenere/ponencies/01_construccion_genero.pdf

Gil Flores, J. (2009). La metodología de investigación mediante grupos de discusión. Enseñanza \& Teaching, (10-11), 199-214. Recuperado de http://e-spacio.uned.es/fez/eserv.php?pid=bibliuned:2 0406\&dsID=metodologia_investigacion.pdf 
Gómez, R. (2016). La representación de la mujer en las revistas femeninas comerciales españolas de alta gama durante la crisis. (Tesis doctoral). Universidad de Málaga. Málaga.

Guerrero, C. (2008). Manual de investigación de medios de comunicación. Sevilla, España: Universidad de Sevilla.

Juan, S. y Roussos, A. (2010). El focus group como técnica de investigación cualitativa. Buenos Aires, Argentina: Universidad de Belgrano.

Justo, A. M. y Vizeu, B. (2012). Cuerpo y cognición social. LIBERABIT, 19(1), 21-32. Recuperado de http:// revistaliberabit.com/es/revistas/RLE_19_1_cuerpo-y-cognicion-social.pdf

Lipovetsky, G. (1999). La tercera mujer. Barcelona, España: Anagrama.

Lomas C. (2005). ¿El otoño del patriarcado? El aprendizaje de la masculinidad y de la feminidad en la cultura de masas y la igualdad entre hombres y mujeres. Cuadernos de Trabajo Social, 18, 259-278. Recuperado de http://biblioteca.ues.edu.sv/revistas/10800248.18.pdf

López , P. (2005). "Los medios de comunicación y la publicidad como pilares fundamentales para lograr el respeto a los derechos humanos de las mujeres". En Figueruelo, Á. (Coord.). Las mujeres en la Constitución europea: estudios multidisciplinares de género (pp. 67-90). Salamanca, España: Universidad de Salamanca.

Loscertales F. (2003). "El lenguaje publicitario: estereotipos discriminatorios que afectan a las mujeres". En Ramírez, M. del M. (Coord.). Medios de comunicación y violencia contra las mujeres (pp. 95-110). Sevilla, España: Instituto Andaluz de la Mujer y Fundación Audiovisual de Andalucía.

Loscertales, F. (2009). La imagen de las mujeres en la era de la comunicación. Revista científica de Información y Comunicación, 6, 427-462. Recuperado de https://idus.us.es/xmlui/bitstream/ handle/11441/12822/file_1.pdf?sequence=1\&isAllowed=y

Martín, M. (2002). La tiranía de la apariencia en la sociedad de las representaciones. Revista Latina de Comunicación Social, (50). Recuperado de: https://www.redalyc.org/articulo.oa?id=81955005

Navarro, M. y Martín, M. (2011). El sexismo publicitario: delimitación de conceptos e indicadores de género. Estudio empírico de la producción científica. Pensar la Publicidad, 5(1), 51-73. Recuperado de https://www.uv.es/formargenero/cas/pensar\%20la\%20publicidad.pdf

Paone, M. E. (2016). La representación de la mujer en la publicidad actual. (Tesis doctoral). Universidad Siglo 21, Buenos Aires, Argentina.

Pease, A. (1991). El lenguaje del cuerpo. Barcelona, España: Paidós.

Piñeiro, M. T. (2010). La utilización de la voz femenina como autoridad en la publicidad radiofónica española. Pensar en la Publicidad, IV (2), 191-214. Recuperado de http://revistas.ucm.es/index. php/PEPU/article/view/PEPU1010220191A/15059

Ruiz, M. y Rubio, J. (2004). La influencia de los medios de comunicación en las imágenes femeninas. Actitudes, hábitos y comportamientos de las mujeres con respecto a la belleza y el cuerpo. 
Clepsydra, 3, 89-107. Recuperado de http://rabida.uhu.es/dspace/bitstream/handle/10272/10857/ La_influencia_de_los_medios.pdf?sequence=2

Salazar, Z. (2007). Imagen corporal femenina y publicidad en revistas. Revista de Ciencias Sociales (Cr), II (116), 71-85. Recuperado de https://www.redalyc.org/pdf/153/15311605.pdf

Sánchez Aranda, J. J. (2003). La publicidad y el enfoque de la imagen femenina. Comunicación y Sociedad, XVI (2), 67-92. Recuperado de http://dadun.unav.edu/bitstream/10171/8059/1/20091015120402.pdf

Sánchez, R. (2015).Canon y estilo de la figura humana en la publicidad gráfica. (Tesis doctoral). Universidad de Sevilla, Sevilla, España.

Santiso, R. (2001). Las mujeres en la publicidad: análisis, legislación y aportaciones para un cambio. Acciones e Investigaciones Sociales, 13, 43-60. Recuperado de https://dialnet.unirioja.es/servlet/ articulo?codigo $=170282$

Soley-Beltran, P. (2010). Cuerpos ideales. Una aproximación interdisciplinaria al estudio de las modelos de moda. Quaderns, 26, 107-134. Recuperado de https://www.raco.cat/index.php/QuadernsICA/ article/view/245013/386737

Torres, R. (2007). Revistas de moda: el contenido al servicio de la forma bella. Ámbitos, 16, 213-225. Recuperado de https://idus.us.es/xmlui/bitstream/handle/11441/67996/revista-comunicacionambitos-16-a_214-226.pdf?sequence=1\&isAllowed=y

Torres, R. (2008). El creciente éxito de las revistas de moda y belleza y la mujer española contemporánea. Global Media Journal, 5 (10). Recuperado de: http://www.redalyc.org/pdf/687/68701002.pdf 